\title{
The Vibrational Spectra of Tetrafluorosuccinic Anhydride
}

\author{
T. WOLDBÆK
}

Department of Chemistry, University of Oslo, Oslo 3, Norway

The IR spectra $\left(4000-200 \mathrm{~cm}^{-1}\right)$ of tetrafluorosuccinic anhydride as a vapour, liquid and dissolved in $\mathrm{CS}_{2}$ were recorded. Additional spectra from the vapour were obtained in the region $400-30 \mathrm{~cm}^{-1}$. Raman spectra of the liquid were recorded, and semiquantitative polarization ratios were measured. The fundamental frequencies were tentatively assigned in terms of $C_{2}$ symmetry based upon Raman polarization data and vapour band contours.

The IR spectra of succinic anhydride as a solid and dissolved in various solvents were recorded between 4000 and $30 \mathrm{~cm}^{-1}$. Raman spectra of the solid were also recorded. The fundamental frequencies were assigned in terms of $C_{2 v}$ symmetry and compared to those of tetrafluorosuccinic anhydride.

Force fields were derived by the overlay technique for succinic and tetrafluorosuccinic anhydride.

We have for some time been interested in the vibrational spectra of five-membered, unsaturated cyclic molecules, and have earlier reported our results for maleimide, ${ }^{1} N$-deuterio ${ }^{1}$ and $N$-chloro ${ }^{2}$ maleimide, succinimide ${ }^{3}$ and $N$-deuterio, ${ }^{3} N$-chloro, $N$-bromo and $N$-iodo succinimide. ${ }^{4}$ These studies have now been extended to include succinic anhydrides. In the present paper we shall report our results for tetrafluorosuccinic anhydride (FSA). Various authors ${ }^{5-7}$ have discussed the IR and Raman spectra of succinic anhydrides, but to our knowledge no IR or Raman data have been reported for FSA.

In the present work we have recorded IR spectra of FSA as a vapour, liquid and dissolved in $\mathrm{CS}_{2}$. Raman spectra were obtained from the neat liquid. Unfortunately we were not able to record spectra of FSA in the solid state since the sample seemed to polymerize upon crystallization.

As an aid to the assignments normal coordinate analyses of FSA were carried out. The data were fitted together with the frequencies from the solution state of succinic anhydride (SA). As the earlier IR data for SA in the solution are rather incomplete, we have also recorded IR spectra of SA dissolved in $\mathrm{CCl}_{4}, \mathrm{CS}_{2}$ and $\mathrm{CH}_{2} \mathrm{Cl}_{2}$.

\section{EXPERIMENTAL}

The sample of FSA was a commercial product from the $\mathrm{K} \& \mathrm{~K}$ laboratories. No impurities were detected by gas chromatography. SA was a commercial product from Fluka $\mathbf{A G}$ and was purified by repeated sublimation on a cold finger.

Raman spectra of the pure liquid FSA were recorded with a Cary Model 81 spectrometer, modified for perpendicular illumination. The $5145 \AA$ line of an argon ion laser was used for excitation. IR spectra were recorded on a Perkin-Elmer Model 225 spectrometer in the region $5000-200 \mathrm{~cm}^{-1}$. Far IR spectra were recorded of the vapour (FSA) with an RIIC interferometer FS-520, equipped with a light pipe gas cell of optical path $c a$. $6 \mathrm{~m}$. FIR spectra $\left(400-30 \mathrm{~cm}^{-1}\right)$ of SA as a polyethylene pellet and dissolved in $\mathrm{C}_{6} \mathrm{H}_{6}$ were recorded using a Perkin-Elmer, Hitachi model FIS-3 spectrometer.

\section{RESULTS}

FSA has recently been studied by electron diffraction. ${ }^{8}$ In contrast to $\mathrm{SA}^{9}$ it was found to have a non-planar ring skeleton although planarity was found for the $\mathrm{O}=\mathrm{C}-\mathrm{O}-\mathrm{C}=\mathrm{O}$ group. Hence the spectra of FSA will be interpreted in terms of $C_{2}$ symmetry, while $\mathrm{SA}$ is considered to possess $C_{2 \mathrm{v}}$ symmetry.

The 27 fundamentals of SA will accordingly divide themselves into the symmetry species: $9 a_{1}+8 b_{2}+$ $5 a_{2}+5 b_{1}$. The $a_{1}$ and $b_{2}$ fundamentals represent in-plane, the $a_{2}$ and $b_{1}$ out-of-plane modes. All the fundamentals are active in the Raman effect while those of species $a_{2}$ are forbidden in the infrared spectra. 


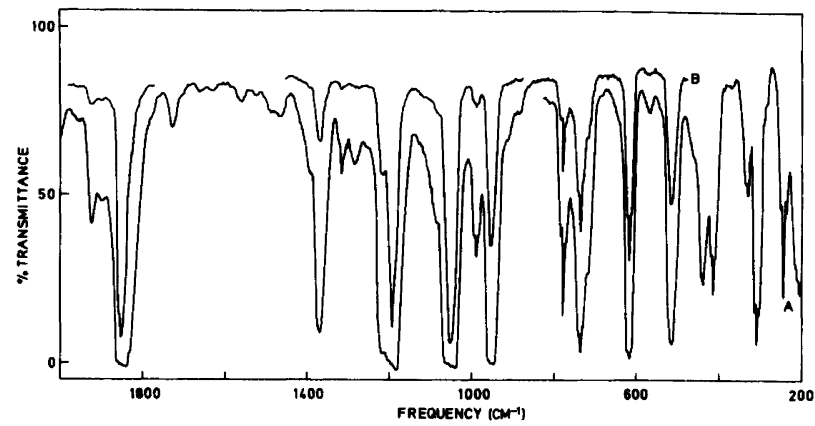

Fig. 1. The infrared spectrum of tetrafluorosuccinic anhydride as a vapour. Path length, $10 \mathrm{~cm}$. Pressure, A, 100 Torr; B, 25 Torr.

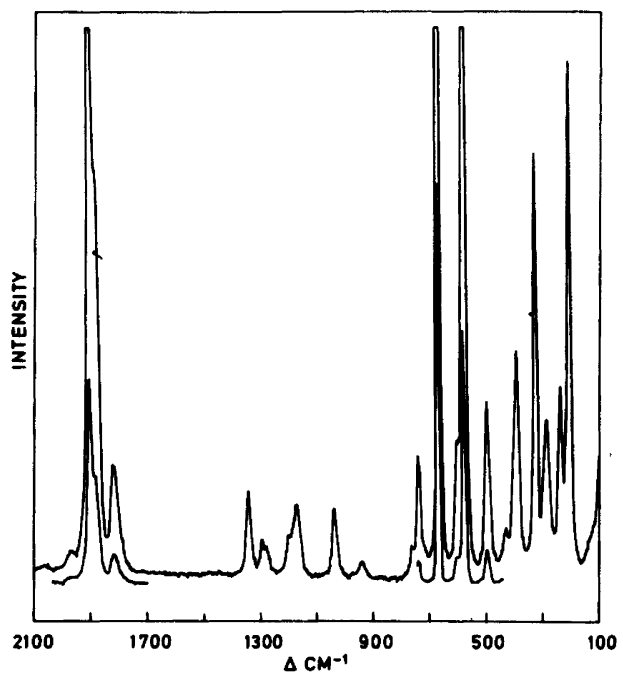

Fig. 2. The Raman spectrum of tetrafluorosuccinic anhydride as a neat liquid.
For FSA all the fundamentals are active both in the Raman and in the IR spectra, and the 27 fundamentals will divide themselves into the symmetry species: $14 a+13 b$. The $a$ species correspond to $a_{1}+a_{2}$ and the $b$ species to $b_{1}+b_{2}$ for SA.

From the structural parameters ${ }^{8}$ of FSA the following moments of inertia are obtained $\left(10^{-40} \mathrm{~g}\right.$ $\left.\mathrm{cm}^{2}\right): I_{A}=331.7, I_{B}=412.7$ and $I_{C}=545.8$. The following PR separations $\left(\mathrm{cm}^{-1}\right)$ were calculated ${ }^{10}$ at $300 \mathrm{~K}: 10$ for $A, 11$ for $B$ and 14 for $C$-bands. The $Q-Q$ separation for the $B$-bands should be $2.5 \mathrm{~cm}^{-1}$. Vibrations belonging to species $a$ give rise to $B$-bands in the IR vapour spectra, while vibrations of species $b$ give $A / C$ hybride bands. Thus, the IR vapour band contours and the Raman polarization measurements offered reasonable good criteria for the assignments of most of the fundamentals for FSA.

Spectral interpretations. As an illustration the IR vapour spectrum of FSA is shown in Fig. 1, whereas a Raman spectrum of the liquid appears in Fig. 2.

Table 1. Infrared ${ }^{\mathrm{a}}$ and Raman spectral data for tetrafluorosuccinic anhydride (FSA).

\begin{tabular}{|c|c|c|c|c|}
\hline \multicolumn{2}{|l|}{ Infrared } & \multirow{2}{*}{$\begin{array}{l}\text { Raman } \\
\text { Liquid }\end{array}$} & \multicolumn{2}{|c|}{ Assignments } \\
\hline Vapour & Liquid & & & \\
\hline $2005 \mathrm{~m}^{b}$ & $1997 \mathrm{~m}$ & 1987 vw P & $\begin{array}{l}v_{14}+v_{15} \\
v_{15}+v_{27}\end{array}$ & $\begin{array}{l}\mathrm{b} \\
\mathrm{a}\end{array}$ \\
\hline $1955 \mathrm{w}$ & 1955 w sh & & $v_{4}+v_{20}$ & $\mathrm{~b}$ \\
\hline $1923 \mathrm{~s}$ & $1923 \mathrm{~m}$ & 1925 s P & $v_{1}$ & a \\
\hline $1899 \mathrm{~m}$ & $\begin{array}{l}1903 \mathrm{~m} \\
1887 \mathrm{w} \text { sh }\end{array}$ & 1903 m P & $\begin{array}{l}v_{16}+v_{22} \\
v_{3}+v_{7}\end{array}$ & $\begin{array}{l}\mathrm{a} \\
\mathrm{a}\end{array}$ \\
\hline $\left.\begin{array}{l}1858 \mathrm{ssh} \\
1852 \mathrm{~s} \\
1847 \mathrm{sh}\end{array}\right\} \mathrm{A} / \mathrm{C}$ & 1840 vs & $1840 \mathrm{~m} \mathrm{D}$ & $v_{15}$ & b \\
\hline
\end{tabular}


Table 1. Continued.

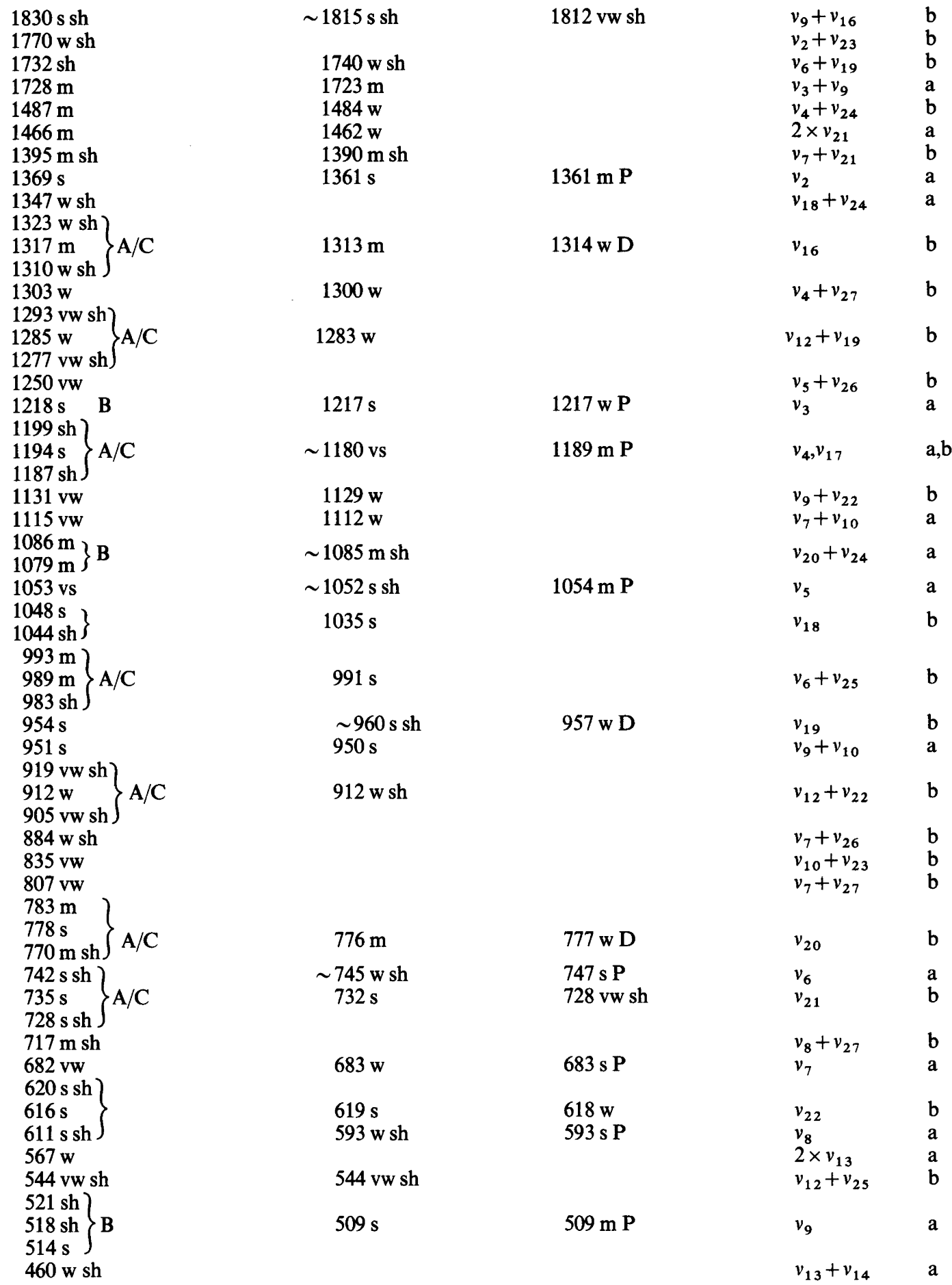

Acta Chem. Scand. A 34 (1980) No. 7 
Table 1. Continued.

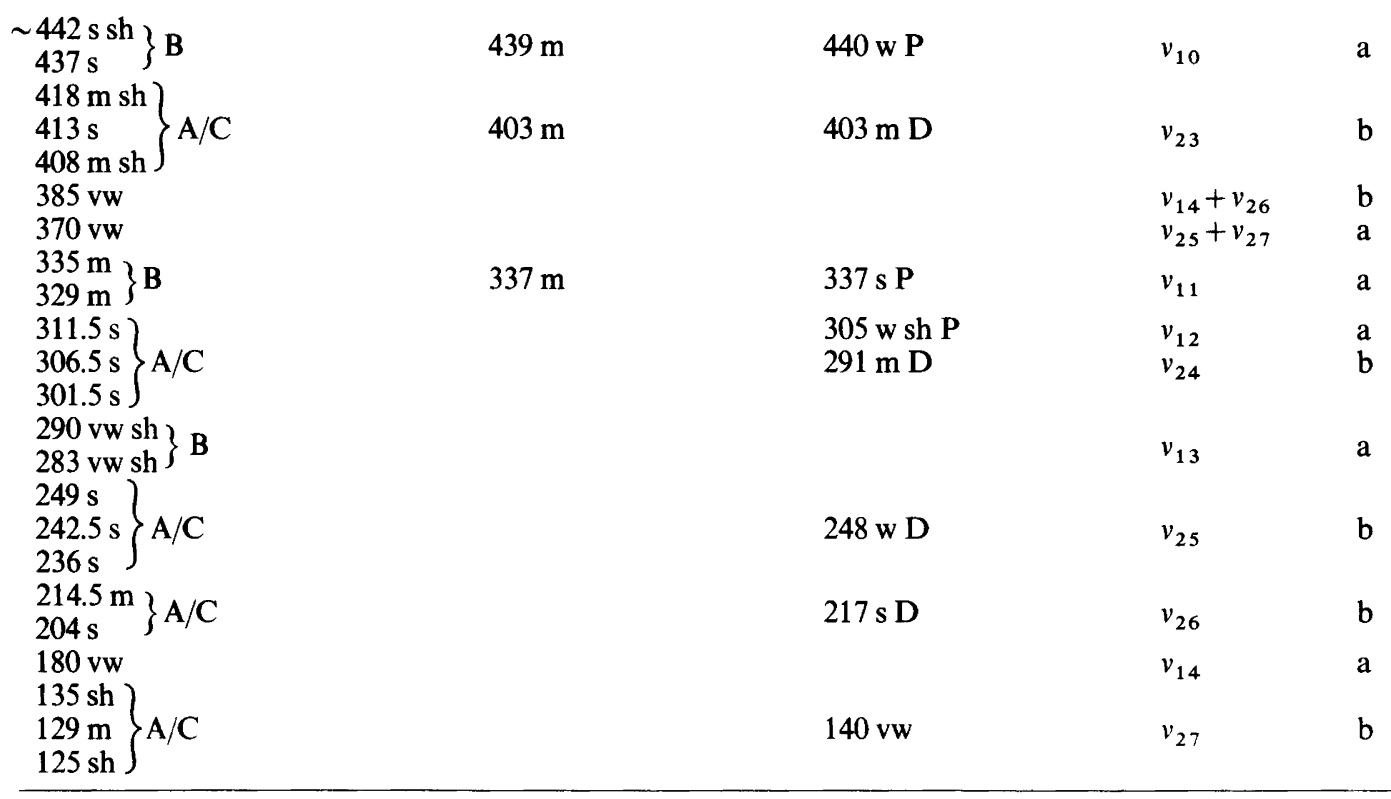

${ }^{a}$ Weak infrared bands in the regions $4000-2000 \mathrm{~cm}^{-1}$ and $1700-1500 \mathrm{~cm}^{-1}$ are omitted. ${ }^{b} \mathrm{w}$, weak; m, medium; s, strong; v, very; sh, shoulder; $\mathrm{P}$, polarized; $\mathrm{D}$, depolarized; A, B and C, vapour band contours.

Table 2. Observed and calculated fundamental frequencies ${ }^{a}$ for tetrafluorosuccinic anhydride (FSA).

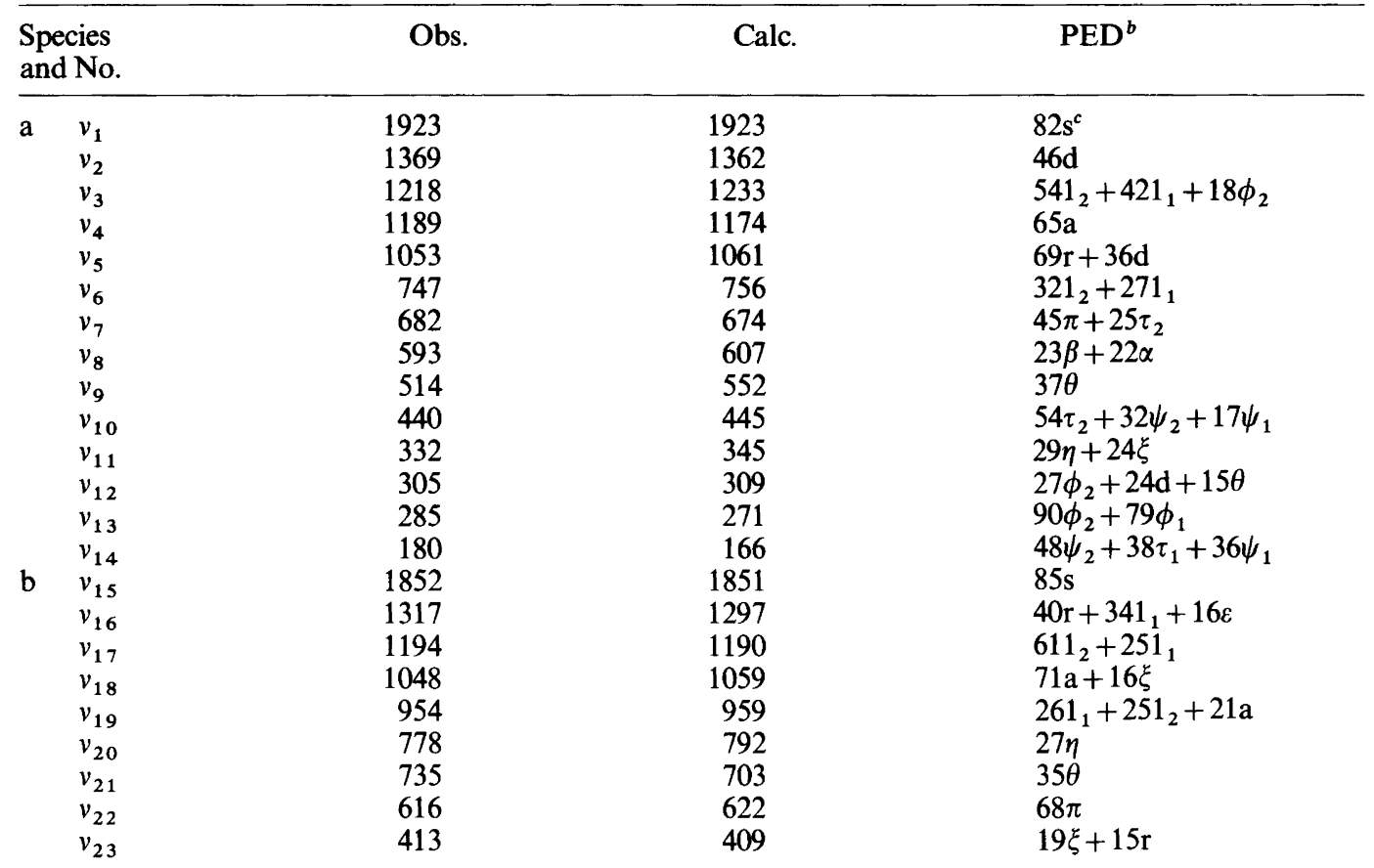


Table 2. Continued.

\begin{tabular}{llll}
$v_{24}$ & 306 & 327 & $21 \psi_{1}+18 \varepsilon+15 \theta$ \\
$v_{25}$ & 242 & 238 & $43 \tau_{1}+27 \tau_{3}+18 \psi_{1}+18 \psi_{2}$ \\
$v_{26}$ & 204 & 204 & $75 \psi_{2}+69 \psi_{1}+15 \phi_{1}$ \\
$v_{27}$ & 129 & 144 & $102 \phi_{2}+71 \phi_{1}+22 \tau_{3}+17 \varepsilon$ \\
\hline
\end{tabular}

${ }^{a}$ When possible, frequencies are taken from the vapour phase data. ${ }^{b}$ The potential energy distribution defined as $X_{\mathrm{ik}}=100 F_{\mathrm{ii}} L_{\mathrm{ik}}^{2} / \lambda_{\mathrm{k}}$. ${ }^{c}$ For meaning of symbols, see Fig. 3. Terms below 15 are neglected.

Table 3. Observed and calculated fundamental frequencies ${ }^{a}$ for succinic anhydride (SA).

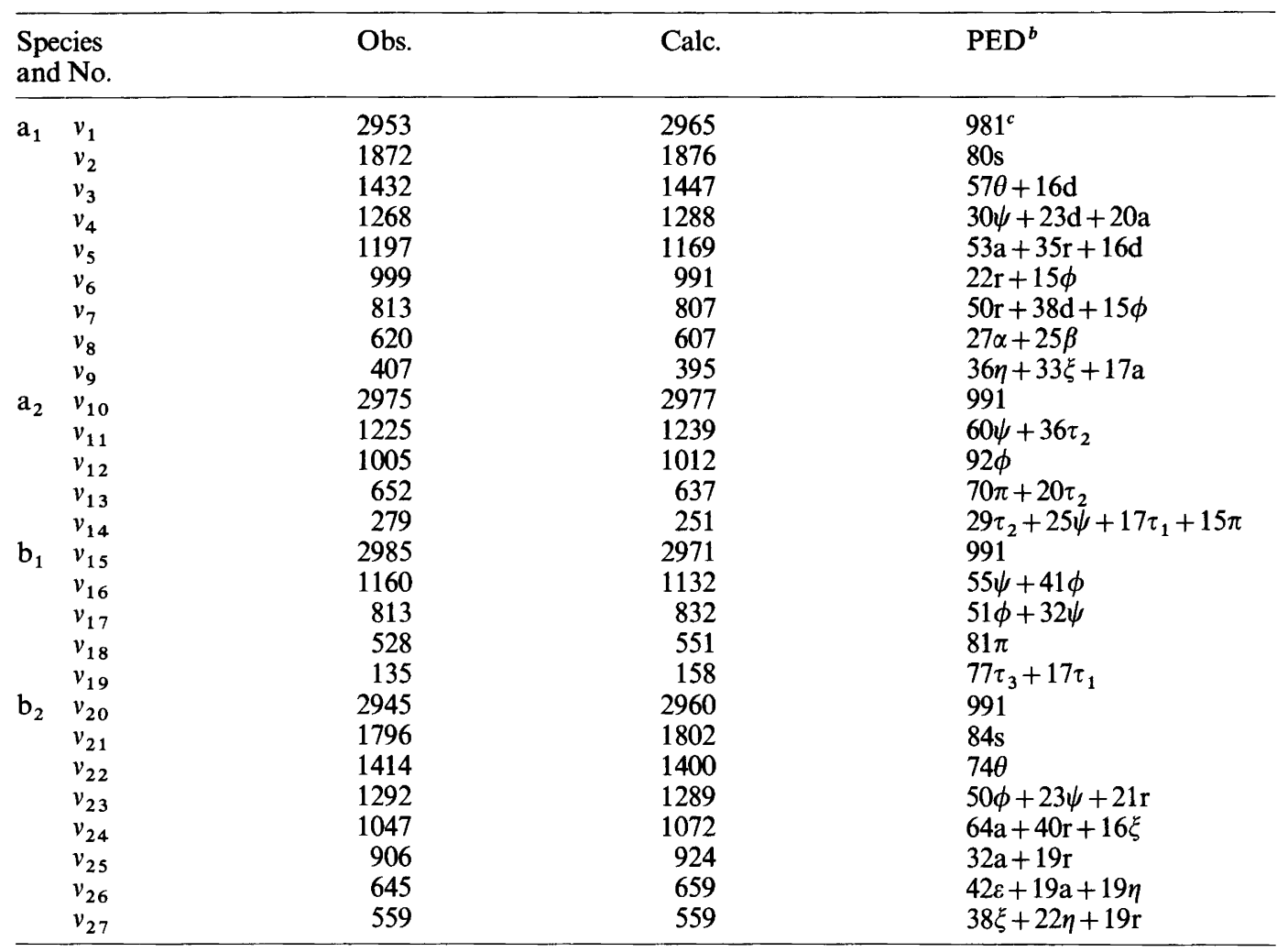

${ }^{a}$ When possible frequencies are taken from solution. ${ }^{b}$ The potential energy distribution defined as $X_{\mathrm{ik}}=F_{\mathrm{ii}} L_{\mathrm{ik}}^{2} / \lambda_{\mathrm{k}}$. ${ }^{c}$ For meaning of symbols, see Fig. 3. $l=l_{1}=l_{2}, \phi=\phi_{1}=\phi_{2}, \psi=\psi_{1}=\psi_{2}$. Terms below 15 are neglected.

The observed IR and Raman frequencies are listed in Table 1 , while the assigned fundamentals are given in Table 2(FSA) and Table 3 (SA) together with the calculated frequencies and the potential energy distribution (PED) among the valence coordinates.

Our assignments of the fundamentals of the inplane modes $\left(a_{1}\right.$ and $\left.b_{2}\right)$ of SA agree with those previously noted. ${ }^{5}$ No complete analyses of the out-of- plane vibrations are reported. We have interpreted the fundamentals of species $a_{2}$ and $b_{1}$ by comparing the spectra with those of the succinimides. ${ }^{3,4}$ The $\mathrm{CH}_{2}$ rock fundamental $v_{12}$ of species $a_{2}$ is assigned to a weak band at $1005 \mathrm{~cm}^{-1}$ only observed in the IR spectra of the solid SA. Similar weak bands at about the same frequency are also observed for all the succinimides, ${ }^{3,4}$ and we suggest that these 
bands should be taken as the $\mathrm{CH}_{2}$ rock frequency rather than that previously indicated at $c a .920$ $\mathrm{cm}^{-1}$.

It is well-known from the maleimides, ${ }^{1,2}$ succinimides, ${ }^{3,4}$ maleic $^{11-13}$ and succinic ${ }^{5,6}$ anhydrides that the $\mathrm{C}=\mathrm{O}$ stretching of species $a_{1}$ is invariably at higher frequency than the $b_{2}$ mode. The same rule applies to FSA, and $v_{1}(a)$ is found at 1923 $\mathrm{cm}^{-1} c a .70 \mathrm{~cm}^{-1}$ higher than $v_{15}(b)$ at $1852 \mathrm{~cm}^{-1}$. A similar frequency splitting is also observed for SA where the two fundamentals are found at ca. $50 \mathrm{~cm}^{-1}$ lower than for FSA, at $1872 \mathrm{~cm}^{-1}\left(a_{1}\right)$ and $1796 \mathrm{~cm}^{-1}\left(b_{2}\right)$. As was earlier discussed for the succinimides, ${ }^{4}$ the $\mathrm{C}=\mathrm{O}$ stretching vibration of species $b_{2}$ shows significantly larger frequency shifts upon solution than the symmetric vibration $\left(a_{1}\right)$. This is also valid for FSA, and the vapour band at $1852 \mathrm{~cm}^{-1}$ is shifted towards $1840 \mathrm{~cm}^{-1}$ in $\mathrm{CS}_{2}$ solution, while the corresponding shift for the vapour band at $1923 \mathrm{~cm}^{-1}$ is only $4 \mathrm{~cm}^{-1}$.

Several very strong bands in the IR spectra of FSA are observed between 1400 and $700 \mathrm{~cm}^{-1}$. Eight fundamentals involving $\mathrm{C}-\mathrm{C}, \mathrm{C}-\mathrm{O}$ and $\mathrm{C}-\mathrm{F}$ streching are to be expected in this region. The $\mathrm{C}-\mathrm{O}$ stretching vibrations are observed at slightly higher frequencies for SA than for FSA. The symmetric mode $(a)$ is found at 1197 and 1189 $\mathrm{cm}^{-1}$, and the asymmetric $(b)$ at 1047 and $1035 \mathrm{~cm}^{-1}$ for SA in solution and liquid FSA, respectively. As indicated by the PED of Tables 2 and 3 , the $\mathrm{C}-\mathrm{O}$ stretchings are well-localized vibrations although for SA they are somewhat mixed with the $\mathrm{C}-\mathrm{C}$ stretchings.

From Table 2 four fundamentals, $v_{3}$ (1218), $v_{6}$ (747), $v_{17}(1194)$ and $v_{19}\left(954 \mathrm{~cm}^{-1}\right)$, can be interpreted as almost pure $\mathrm{C}-\mathrm{F}$ stretching vibrations with only small mixings with the $\mathrm{C}-\mathrm{C}$ stretchings. The four vibrations assigned to $\mathrm{C}-\mathrm{F}$ stretching correspond to either relatively strong bands in the IR spectra of the vapour or to polarized Raman bands. This is in agreement with a non-planar structure of FSA as was also found from the electron diffraction investigation. ${ }^{8}$ If the molecule possessed $C_{2 v}$ symmetry, only three of the four $\mathrm{C}-\mathrm{F}$ stretchings should give IR active vibrations, and only one should give a polarized Raman band.

The ring and $\mathrm{C}=\mathrm{O}$ in-plane bending vibrations will be expected in the region $800-400 \mathrm{~cm}^{-1}$. For FSA two additional FCF bending vibrations at 735 and $514 \mathrm{~cm}^{-1}$ are complicating this spectral area. For all the similar five-membered rings investigated $^{1-6,11-13}$ a characteristic, usually weak
IR and strong Raman band is observed in the narrow frequency region $600-650 \mathrm{~cm}^{-1}$. This band has been assigned to an in-plane ring bending, mostly involving the $\mathrm{C}-\mathrm{O}-\mathrm{C}$ part of the molecule. The corresponding bands of FSA and SA $\left(v_{8}\right)$ are observed at $593 \mathrm{~cm}^{-1}$ and at $620 \mathrm{~cm}^{-1}$, respectively.

The symmetric $\mathrm{C}=\mathrm{O}$ in-plane bending vibration was observed at $c a .400-420 \mathrm{~cm}^{-1}$ for maleimide, ${ }^{1}$ maleic anhydride, ${ }^{11}$ succinimide, ${ }^{3} \mathrm{SA}$ and their deuterated species. ${ }^{1,3,5,11}$ For FSA this mode is situated at $332 \mathrm{~cm}^{-1}$. A considerable frequency shift for this vibration was also noticed for the halogenated maleimides, ${ }^{2}$ succinimides ${ }^{4}$ and maleic anhydrides. ${ }^{12,13}$ This shift can, except for FSA, be explained by a coupling between the $\mathrm{C}=\mathrm{O}$ in-plane bending and the $\mathrm{N}-\mathrm{X}$ or $\mathrm{C}-\mathrm{X}$ stretching vibrations. For FSA a mixing with the FCF bending vibration at $514 \mathrm{~cm}^{-1}$ could explain the low frequency of the symmetric $\mathrm{C}=\mathrm{O}$ bending vibration although such a mixing is not calculated by the PED (Table 2).

The far IR spectra of FSA are quite different from those of SA due to the many CCF bending vibrations in this region. All bands below $350 \mathrm{~cm}^{-1}$ (FSA) are considered to be fundamentals (Table 1). The IR vapour band contours and the Raman polarization data make the assignments in this spectral area rather straight-forward.

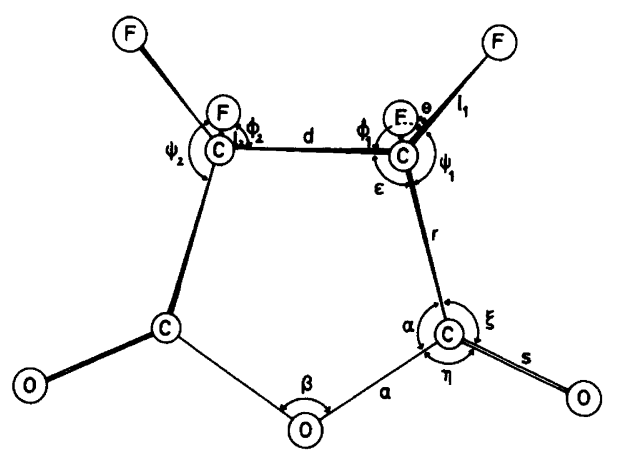

Fig. 3. Internal coordinates for tetrafluorosuccinic anhydride. The following coordinates are not shown on the figure: $\pi$, the bending of $C^{\prime}=0$ relative to the plane formed by the atoms $\mathrm{C}-\mathrm{C}^{\prime}-0 . \tau_{1}$; the normalized sum of the two torsions around the $\mathrm{C}-\mathrm{O}$ bond. $\tau_{2}$; the normalized sum of the nine torsions around the $\left(\mathrm{F}_{2}\right) \mathrm{C}-\mathrm{C}\left(\mathrm{F}_{2}\right)$ bond. $\tau_{3}$; the normalized sum of the six torsions around the $(\mathrm{O}) \mathrm{C}-\mathrm{C}\left(\mathrm{F}_{2}\right)$ bond. 
Table 4. Valence force constants for succinic anhydride (SA) and tetrafluorosuccinic anhydride (FSA).

\begin{tabular}{|c|c|c|c|}
\hline \multirow{3}{*}{ Force type } & \multicolumn{3}{|l|}{ Constants } \\
\hline & \multirow[t]{2}{*}{ Symbol $^{\mathrm{a}}$} & \multicolumn{2}{|l|}{ Value $^{b}$} \\
\hline & & FSA & SA \\
\hline \multirow[t]{4}{*}{ Stretch } & $K_{\mathrm{a}}$ & 5.68 & $-^{c}$ \\
\hline & $K_{\mathrm{s}}$ & 12.6 & 11.8 \\
\hline & $K_{\mathrm{r}}=K_{\mathrm{d}}$ & 5.0 & - \\
\hline & $K_{1}$ & 5.5 & 4.8 \\
\hline \multirow[t]{4}{*}{ Bend } & $H_{\eta}=H_{\xi}$ & 0.92 & - \\
\hline & $H_{\psi}^{\prime}=H_{\phi}$ & 1.07 & 0.57 \\
\hline & $H_{\theta}$ & 1.85 & 0.5 \\
\hline & $H_{\alpha}=H_{\beta}=H_{\varepsilon}$ & 1.33 & - \\
\hline Outo & $\pi$ & 0.44 & - \\
\hline \multirow[t]{3}{*}{ Torsion } & $\tau_{1}$ & 0.06 & - \\
\hline & $\tau_{2}$ & 0.69 & 0.11 \\
\hline & $\tau_{3}$ & 0.06 & 0.013 \\
\hline \multirow[t]{5}{*}{ Stretch-stretch } & $F_{\mathrm{a},}$ & 1.3 & - \\
\hline & $F_{\mathrm{a}, \mathrm{s}}$ & 0.71 & - \\
\hline & $F_{\mathrm{r}, 1}=F_{\mathrm{d}, 1}{ }^{\mathrm{d}}$ & 0.3 & 0 \\
\hline & $F_{1_{1}, 1_{2}} \mathrm{~d}$ & 0.3 & 0.1 \\
\hline & $F_{\mathrm{s}, \mathrm{s}}$ & 0.15 & - \\
\hline \multirow{4}{*}{ Stretch-bend } & $F_{\mathrm{a}, \alpha}=F_{\mathrm{a}, \beta}=F_{\mathrm{r}, \alpha}=F_{\mathrm{r}, \varepsilon}=F_{\mathrm{d}, \varepsilon}$ & 0.56 & - \\
\hline & $F_{\mathrm{a}, \eta}=F_{\mathrm{r}, \xi}$ & 0.31 & $\overline{0}$ \\
\hline & $\begin{array}{l}F_{1, \psi}=F_{1, \phi}{ }^{a} \\
F\end{array}$ & $\begin{array}{l}0.23 \\
023\end{array}$ & $\begin{array}{l}0 \\
0.03\end{array}$ \\
\hline & $F_{1, \theta} \mathrm{r}, \psi_{\mathrm{d}}^{-1} \mathrm{~d}, \phi$ & 1.13 & 0 \\
\hline \multirow[t]{3}{*}{ Bend-bend } & $F_{\psi_{1}, \psi_{2}}=F_{\phi_{1}, \phi_{2}}{ }^{d}$ & 0.6 & -0.03 \\
\hline & $F_{\tau, \psi}=F_{\varepsilon, \phi}$ & 0.3 & 0 \\
\hline & $F_{\phi_{1}, \phi_{1}}=F_{\phi_{2}, \phi_{2}}$ & 0 & -0.06 \\
\hline
\end{tabular}

${ }^{a}$ For meaning of symbols, see Fig. 3. Unnumbered indices, $l, \psi$ and $\phi$ mean $F_{l}=F_{l_{1}}=F_{l_{2}}$ etc. ${ }^{b}$ In units of mdyn $\AA^{-1}$ (stretch constants), mdyn $\mathrm{rad}^{-1}$ (stretch-bend interaction) and mdyn $\AA \mathrm{rad}^{-2}$ (bending and torsion constants). ${ }^{c}$ The force constant is the same as for FSA. ${ }^{d}$ Interaction between adjacent coordinates.

\section{NORMAL COORDINATE ANALYSES}

We wanted to use force constant calculations as a tool for obtaining more reliable assignments. Because of the similarity in the structure of FSA and SA, it was possible to construct an almost common force field for the two compounds. Except for the force constants directly involving the $\mathrm{CF}_{2}$ or $\mathrm{CH}_{2}$ groups, only the $\mathrm{C}=\mathrm{O}$ stretching force constant is different for FSA and SA. A considerably larger value for this constant had to be used for FSA than for $\mathrm{SA}$ in order to reproduce the much higher $\mathrm{C}=\mathrm{O}$ stretching frequencies for FSA.

We have strictly limited the number of independent force constants, and the final force fields contain 31 parameters given in Table 4. The symbols are defined in Fig. 3. For FSA we have used frequencies from the vapour phase in the calculations whereas for SA we have used data from solution since no vapour phase data were available for this compound. Hence, the transferability of the force constants are somewhat uncertain since both FSA and SA show considerable frequency shifts when passing from one phase to the other. However, considering the approximations used, the fit between the observed and calculated frequencies is satisfactory.

Only a few normal coordinate analyses are reported for molecules containing $\mathrm{CF}_{2}$ groups, ${ }^{14-20}$ and our final force constants seem to be of reasonable magnitudes compared to them. $\mathrm{C}-\mathrm{F}$ stretching force constants are previously found from 4.288 for $\mathrm{CH}_{3} \mathrm{CF}_{2} \mathrm{CH}_{3}{ }^{17}$ to $6.40 \mathrm{mdyn} / \AA$ for $\mathrm{N}=\mathrm{C}-\mathrm{CF}_{2}$ $-\mathrm{CF}_{2}-\mathrm{C}=\mathrm{N}^{20}$, and our value of $5.5 \mathrm{mdyn} / \AA$ can therefore be considered as very normal for a 
$\mathrm{C}-\mathrm{F}$ stretching. The CCF bending force constant is almost always found to be $c a .1 .1 \mathrm{mdyn} \AA / \mathrm{rad}^{2}$ in agreement with the value of 1.07 , suitable for FSA. The FCF bending force constant varies from $1.40\left(\mathrm{CF}_{2} \mathrm{Br}-\mathrm{CF}_{2} \mathrm{Br}\right)^{14}$ to $2.331 \mathrm{mdyn} \AA / \mathrm{rad}^{2}$ $\left(\mathrm{CH}_{3} \mathrm{CF}_{2} \mathrm{CH}_{3}\right),{ }^{17}$ a value of 1.85 thus being very reasonable. Quite different interaction force constants are used for the $\mathrm{CF}_{2}$ groups. ${ }^{14-20}$ Especially the $\mathrm{C}-\mathrm{C}$ stretching/CCF bending interaction force constant seems to be indeterminable. We have therefore chosen to set this interaction $\left(F_{\mathrm{r}, \psi}, F_{\mathrm{d}, \phi}\right)$ constant equal to the $\mathrm{CF} / \mathrm{CCF}$ interactions $\left(F_{1, \psi}\right.$, $\left.F_{1, \phi}\right)$.

The observed and calculated fundamental frequencies are given in Tables 2 (FSA) and 3 (SA) together with the potential energy distribution among the valence coordinates.

Acknowledgements. The author is grateful to P. Klæboe and to C. J. Nielsen for helpful discussions and to the late K. Ružička for the preparative work. Financial support from the Norwegian Research Council for Science and the Humanities is acknowledged.

\section{REFERENCES}

1. Woldbæk, T., Klæboe, P. and Nielsen, C. J. J. Mol. Struct. 27 (1975) 283.

2. Woldbæk, T., Klæboe, P. and Nielsen, C. J. $J$. Mol. Struct. 28 (1975) 269.

3. Woldbæk, T., Klæboe, P. and Christensen, D. H. Acta Chem. Scand. A 30 (1976) 531.

4. Woldbæk, T., Klæboe, P. and Christensen, D. H. Acta Chem. Scand. A 30 (1976) 547.

5. Di Lauro., Califano, S. and Adembri, G. J. Mol. Struct. 2 (1968) 173.

6. Fortunato, B., Giorgini, M. G. and Mirone, P. J. Mol. Struct. 25 (1975) 229.

7. Adembri, G., Sbrana, G. and Califano, S. Ric. Sci. 3 (1963) 431.

8. Almenningen, A., Fernholt, L. and Seip, H. M. J. Mol. Struct. 49 (1978) 333.

9. Brendhaugen, K., Fikke, M. K. and Seip, H. M. Acta Chem. Scand. 27 (1973) 1101.

10. Ueda, T. and Schimanouchi, T. J. Mol. Spectrosc. 28 (1968) 350.

11. Rogstad, A., Klæboe, P., Baranska, H., Bjarnov, E., Christensen, D. H., Nicolaisen, F., Nielsen, O. F., Cyvin, B. N. and Cyvin, S. J. J. Mol. Struct. 20 (1974) 403.

12. Rogstad, A., Klæboe, P., Cyvin, B. N., Cyvin, S. J. and Christensen, D. H. Spectrochim. Acta Part A 28 (1972) 123.
13. Rogstad, A., Klæboe, P., Cyvin, B. N., Cyvin, S. J. and Christensen, D. H. Spectrochim. Acta Part A 28 (1972) 111.

14. Shurvell, H. F., Cahill, F., Devarajan, V. and James, D. W. Can. J. Chem. 54 (1976) 2220.

15. Klæboe, P. and Smith, Z. Spectrochim. Acta Part A 34 (1978) 489.

16. Powell, D. L., Gustavsen, J. E., Klæboe, P. and Nielsen, C. J. J. Raman Spectrosc. 7 (1978) 111.

17. Crowder, G. A. and Jackson, D. Spectrochim. Acta Part A 27 (1971) 2505.

18. Crowder, G. A. J. Mol. Struct. 15 (1973) 351.

19. Bjørklund, S., Augdahl, E., Christensen, D. H. and Sørensen, G. O. Spectrochim. Acta Part A 32 (1976) 1021.

20. Gustavsen, J. E., Klæboe, P., Nielsen, C. J. and Powell, D. L. Spectrochim. Acta Part A 35 (1979) 109. 